\title{
OCCUPATIONAL BURNOUT AND WORK-HOME INTERACTIONS IN HOSPITAL-EMPLOYED NURSES
}

\author{
Anna Leonarda Nowacka ${ }^{\mathrm{A}, \mathrm{D}, \mathrm{F}}$, Kinga Kołodziej ${ }^{\mathrm{B}, \mathrm{D}}$, Anna Piskorz ${ }^{\mathrm{E}, \mathrm{F}}$, Renata Wolfshaut ${ }^{\mathrm{C}, \mathrm{F}}$
}

Department of Nursing Management and Epidemiological Nursing, Faculty of Health Sciences, Jagiellonian University Medical College, Krakow, Poland

\section{Authors' contribution:}

A. Study design/planning • B. Data collection/entry $\bullet$ C. Data analysis/statistics $\bullet$ D. Data interpretation $\bullet$ E. Preparation of manuscript $\bullet$ F. Literature analysis/search $\bullet$ G. Funds collection

\author{
Address for correspondence: \\ Dr. Anna Leonarda Nowacka \\ Department of Nursing Management \\ and Epidemiological Nursing \\ Faculty of Health Sciences \\ Jagiellonian University Medical College \\ 25 Kopernika St. \\ 31-501 Krakow, Poland \\ e-mail: anna.nowacka@uj.edu.pl \\ SUBMITTED: 26.02 .2020 \\ ACCEPTED: 17.03 .2020 \\ DOI: https://doi.org/10.5114/ppiel.2020.96092
}

\begin{abstract}
Introduction: Occupational burnout mainly affects professions that involve helping others. Work-life balance may be defined as an opportunity to reach one's aims in various spheres. Because of the character of nursing and its strong feminisation in Polish culture, nurses are expected to combine emotional commitment to their job while also fulfilling family duties.

Aim of the study: The objective of the study was to analyse the relations between occupational burnout and workhome interactions in hospital-employed nurses.

Material and methods: The study was conducted as a diagnostic survey in a group of 179 hospital-employed nurses. The interviewers applied a self-designed questionnaire, the Maslach Burnout Inventory, and the SWING questionnaire. Results: The average age of respondents was 35.4 ( $S D=10.46)$ years. Bachelor's degree was the most common education level (52.5\%). Workplaces included non-invasive (44.1\%) and medical treatment wards (55.9\%). 22.3\% of nurses declared extra employment. Average subscale values showed average emotional exhaustion (22.9), low depersonalisation (8.1), and low personal accomplishment (27.63). There was a positive correlation between emotional exhaustion $(r=0.51, p<0.01)$ and depersonalisation $(r=0.32, p=0.001)$ and a negative work-home relation. Moreover, depersonalisation had a positive $(r=0.51, p=0.01)$ and personal accomplishment had a negative $(r=-0.28, p=0.01)$ influence on negative home-work relation. All burnout subscales affected work-home interactions. No significant correlation was observed between positive home-work relation and the analysed burnout dimensions.

Conclusions: The examined nurses reported high emotional exhaustion, depersonalisation, and lowered personal accomplishment. These findings prove a significant correlation between work-home interaction and professional burnout.
\end{abstract}

Key words: burnout, nurse, work-home interaction.

\section{INTRODUCTION}

The term "burnout syndrome" was first used in scientific publications by the American psychiatrist H. J. Freudenberger in 1974 [1]. Another author of a multidimensional concept of occupational burnout is Christina Maslach, an American psychologist. She defined burnout as "a psychological syndrome involving emotional exhaustion, depersonalisation, and a diminished sense of personal accomplishment that occurs among various professionals who work with other people in challenging situations" $[2,3]$. The syndrome may affect various professionals; however, the most susceptible to burnout are those whose jobs involve helping others. Working under pressure and taking responsibility for the lives and health of other people accompanied by shift work and lack of support from superiors may result in a high level of emotional exhaustion and, in consequence, lead to occupational burnout syndrome. The syndrome can be observed in the form of health problems, conflicts at work, a decrease in the quality and efficiency with which one's tasks are performed, and, in extreme cases, it may cause professionals to resign from their jobs $[4,5]$.

There are four symptoms of occupational burnout in nurses: psychophysical exhaustion, lack of commitment as far as relations with patients are concerned, 
no sense of job efficiency, and disappointment. In the case of occupational burnout, anger and exasperation result from chronic emotional exhaustion, a sense of futility of one's actions, embarrassment, being taken for granted, and self-blame. Occupational burnout syndrome is also connected with a sense of confusion about the reasons for such a condition. Occupational burnout prevention is addressed mainly to people who have suffered from this syndrome in the past, and it focuses on modifying risk factors and enhancing protective measures [6].

Nowadays, studies concentrate on how to maintain a work-life balance in professionally active people, and on the consequences of its disturbance [7]. Work-life balance is a complex phenomenon and it has no universal definition [8, 9]. Greenhaus et al. define work-life balance as "the extent to which an individual is equally engaged in - and equally satisfied with - his or her work and family role". Work-life balance includes three components: time (i.e. equal division of time between work and family roles), involvement (i.e. equal psychological involvement in roles), and satisfaction (i.e. equal satisfaction gained from both roles). In order to achieve work-life balance all three components must be taken into consideration [9]. Moreover, work-life balance means a chance to achieve one's objectives in various spheres of life. Therefore, employees have to reconcile the requirements resulting from their work with their family life as well as with other social roles, the necessity to educate themselves and develop their competences, and the need to find time to relax and participate in physical activity. The conflict that they often experience, caused by the necessity to take on different roles at work and in the family, leads to a decrease in satisfaction from both these spheres. The character of a nursing job involves its strong feminisation and, in consequence, leads to nurses' firm emotional commitment to their job and, simultaneously, their need to meet social expectations to fulfil numerous family duties resulting from stereotypes deeply rooted in Polish culture. However, maintaining a proper balance between professional and family duties is possible only thanks to good time management and loyal support of family members and co-workers. Meta-analyses of the studies on work-home interactions define three groups of consequences resulting from negative work-home and home-work interactions: workrelated, family-related, and non-specific. The work-related consequences include, for example, correlations between negative work-home, home-work interactions and occupational burnout [10]. Meta-analyses of the studies on positive work-home, home-work interactions proved the positive correlation of these interactions with job satisfaction, workplace attachment, satisfaction with life, and physical and mental health $[11,12]$.

\section{AIM OF THE STUDY}

The objective of the study was to analyse the relations between occupational burnout and work-home interactions in hospital-employed nurses.

\section{MATERIAL AND METHODS}

The study was conducted in four hospitals situated in the Małopolska region. The study was approved by the Bioethics Committee of Jagiellonian University Medical College and the managers of the medical facilities involved. The criteria for participation in the research included: written consent for participation, nursing profession, and proper workplace. As many as 200 people met the criteria, 179 of whom $(89.5 \%$ of those who met the criteria) were classified for the analysis.

The study was conducted with the application of a standard questionnaire consisting of three parts. The first part included questions regarding socio-demographic variables: gender, age, marital status, having children, and education, as well as questions that dealt with occupational variables such as the period of employment, workplace, system of work, managerial positions, doing overtime, and extra employment. For the sake of statistical analysis, the respondents were divided into three groups depending on their education: secondary vocational education, higher vocational BA education, and higher MA education.

The second part consisted of MBI-HSS (Maslach Burnout Inventory Human Services Survey), which examined three aspects of occupational burnout: emotional exhaustion (EE), depersonalisation (DEP), and personal accomplishment (PA). The questionnaire consisted of 22 statements. Each of the statements was connected with one of the three separate subscales. The emotional exhaustion subscale included nine statements: numbers $1,2,3,6,8,13,14,16$, and 20. The depersonalisation subscale included five statements: numbers 5, 10,11, 15, and 22. The personal accomplishment subscale included eight statements: numbers $4,7,9,12,17,18,19$, and 21 . The frequency with which the respondents experience the feelings or attitudes described by the statements is assessed on a seven-point scale. There are seven frequency options ranging from 0 to 6 . They appear in the following order: 0 - never, 1 - a few times a year, 2 - once a month or less, 3 - a few times a month, 4 - once a week, 5 - a few times a week, and 6 - every day. The results of the subscales were analysed in the following way: first the average value was defined for each of the examined subscales, and then, according to the results, the categories were determined for relevant levels on each subscale. The results were interpreted according to the following reference norms: for the emotional exhaustion subscale scores of 27 or more meant a high level, average level ranged from 
17 to 26, and scores between 0 and 16 were interpreted as a low level. For the depersonalisation subscale scores of 13 or more meant a high level, 7-12 meant an average level, and 0-6 a low level. For the personal accomplishment subscale scores of 39 and more meant a high level, 32-38 - average level, and 0-31 - low level. High scores on the emotional exhaustion and depersonalisation subscales accompanied by low scores on the personal accomplishment subscale indicated occupational burnout [13]. The internal consistency of Polish studies reached a Cronbach's $\alpha$-coefficient of above 0.7 [14].

The third part of the study was the SWING questionnaire, consisting of 22 questions, in which the respondents were asked how often they experience particular states or events. The questionnaire was made up of four independent subscales. They included: positive influence of work on personal life, negative influence of work on personal life, positive influence of personal life on work, and negative influence of personal life on work. Respondents answered the questions using a four-point scale (never, sometimes, often, always). Negative work-home interactions were assessed in the following questions: How often does it happen that: 1. You are irritable at home because your work is demanding?, 2. You find it difficult to fulfil your domestic obligations because you are constantly thinking about your work?, 4. You have to cancel appointments with your spouse/family/ friends due to work-related commitments?, 7. Your work schedule makes it difficult for you to fulfil your domestic obligations?, 8. You do not have the energy to engage in leisure activities with your spouse/family/friends because of your job?, 9. You have to work so hard that you do not have time for any of your hobbies?, and 11. Your work obligations make it difficult for you to feel relaxed at home?

In turn, negative home-work interactions were assessed in the following questions: How often does it happen that: 15 . You have difficulty concentrating on your work because you are preoccupied with domestic matters?, 17. The situation at home makes you so irritable that you take your frustrations out on your colleagues?, 19. Problems with your spouse/family/ friends affect your job performance?, and 22. You do not feel like working because of problems with your spouse/family/friends?

On the other hand, positive work-home interactions could be indicated by the following questions: How often does it happen that: 3. You manage your time at home more efficiently as a result of the way you do your job?, 5. You are better able to interact with your spouse/family/friends as a result of the things you have learned at work?, 6. You are better able to keep appointments at home because your job requires this as well?, 10. You fulfil your domestic obligations better because of the things you have learned on your job?, and 13. After a pleasant working day/working week, you feel more in the mood to engage in activities with your spouse/family/friends?

And finally the questions which characterised positive work-home interactions: How often does it happen that: 14 . After spending a pleasant weekend with your spouse/family/friends, you have more fun in your job?, 16. You take your responsibilities at work more seriously because you are required to do the same at home?, 18. You are better able to keep appointments at work because you are required to do the same at home?, and 20. You manage your time at work more efficiently because at home you have to do that as well?

The reliability and criterion validity of this research were confirmed in Polish studies - internal consistency measured by Cronbach's $\alpha$-coefficient reached 0.79 for the whole scale and between 0.73 and 0.89 for particular subscales $[15,16]$.

The distribution of quantity variables was described by quoting the average values and standard deviation or, if the value distribution was different from a regular distribution, by quoting the median and interquartile range. The Shapiro-Wilk test was applied to confirm the variable's congruence with normal distribution. For each of the four analysed subscales of work-home interactions the scores obtained for particular questions were totalled and then divided by the number of responses. In the case of the subscales describing negative work-home interactions and negative home-work interactions, higher scores corresponded to more frequent (more intense) incidence of negative interactions. On the other hand, in the case of the subscales describing positive work-home interactions and negative home-work interactions, higher scores meant more frequent (more intense) incidence of positive interactions. The correlation between the subscales of occupational burnout and the subscales of work-home interactions as well as the period of employment and financial status were examined by means of Spearman's rank correlation coefficient. Occupational burnout was also examined in terms of socio-demographic features and workplace conditions/character (shift work, extra employment) by means of Student's t-test, ANOVA, Mann-Whitney $U$ test, or Kruskal-Wallis ANOVA test, depending on the distribution of the examined variable. Statistical analyses were carried out with the application of IBM SPSS Software version 23. The significance level was estimated as $\alpha=0.05$ for two-tailed tests.

\section{RESULTS}

\section{Socio-demographic characteristics}

The study was conducted in a group of 179 professionally active nurses working in hospitals in the Małopolska region. The group consisted of 177 women 
(98.8\%) and two men (1.2\%). The average age of respondents was 35.4 (SD $=10.46$ years, $64.2 \%$ of them were married, and $48.0 \%$ had at least one child. Bachelor's degree was the most common education level (52.5\%). The workplace included non-invasive (44.1\%) and medical treatment wards (55.9\%). All respondents worked shifts. Their average period of employment was 12 years $(S D=11.29) .22 .3 \%$ of nurses declared extra employment. The data are presented in Table 1.

\section{Occupational burnout}

According to Maslach Burnout Inventory (MBI), the general rate of occupational burnout in the examined group of nurses reached $X=45.6$ ( $S D=16.96$ ). High emotional exhaustion was observed in $32 \%$ of respondents. As far as the depersonalisation subscale is concerned, $22.0 \%$ of respondents were classified as a high level. Almost two thirds of respondents were classified at a low level of personal accomplishment (Table 2).

\section{Work-home, home-work interactions}

The distribution of subscale values for negative work-home interaction did not deviate from normal distribution, with an average value of $1.05(S D=0.47)$. The minimum value was 0 , whereas the maximum value reached 2.5 (Table 3 ). The most frequent comments made by nurses implied that they were irritated at home because of work requirements, their work time made it harder for them to perform their household chores, and that work duties prevented them from relaxing at home.

The distribution of subscale values for negative home-work interaction was significantly different from normal distribution. The median was 0.5 , the lower quartile was 0.25 , and the upper quartile was 0.75 . The lowest value was 0 , whereas the maximum values reached 1.75 (Table 3). The most frequent comments made by nurses implied that they found it difficult to concentrate at work because they were absorbed in their home problems, their problems with their partners (family or friends) had a negative impact on their performance at work, or that they did not work well enough due to problems with their partners (family, friends).
The distribution of subscale values for positive work-home interaction was similar to normal distribution, and the average value reached $1.28(S D=0.47)$.

Table 1. Socio-demographic characteristics of the examined group of nurses

\begin{tabular}{|c|c|c|c|c|}
\hline $\begin{array}{l}\text { Socio-demographic } \\
\text { variables }\end{array}$ & $N$ & $\%$ & Average & SD \\
\hline \multicolumn{5}{|l|}{ Gender } \\
\hline Female & 177 & 98.8 & - & - \\
\hline Male & 2 & 1.2 & - & - \\
\hline Age & & & 35.4 & 10.46 \\
\hline \multicolumn{5}{|l|}{ Marital status } \\
\hline Single & 64 & 35.8 & - & - \\
\hline Married & 115 & 64.2 & - & - \\
\hline \multicolumn{5}{|l|}{ Children } \\
\hline Yes & 86 & 48.0 & - & - \\
\hline No & 93 & 52.0 & - & - \\
\hline \multicolumn{5}{|l|}{ Education } \\
\hline $\begin{array}{l}\text { Secondary } \\
\text { vocational education }\end{array}$ & 38 & 21.2 & - & - \\
\hline $\begin{array}{l}\text { Higher education - } \\
\text { BA degree }\end{array}$ & 94 & 52.5 & - & - \\
\hline $\begin{array}{l}\text { Higher education - } \\
\text { MA degree }\end{array}$ & 47 & 26.3 & - & - \\
\hline Period of employment & & & 12.0 & 11.29 \\
\hline \multicolumn{5}{|l|}{ Workplace } \\
\hline Non-invasive ward & 79 & 44.1 & - & - \\
\hline $\begin{array}{l}\text { Medical treatment } \\
\text { ward }\end{array}$ & 100 & 55.9 & - & - \\
\hline \multicolumn{5}{|l|}{ Extra employment } \\
\hline Yes & 40 & 22.3 & - & - \\
\hline No & 139 & 77.7 & - & - \\
\hline
\end{tabular}

Table 2. The incidence of three dimensions of occupational burnout in the examined group of nurses according to Maslach

\begin{tabular}{lcc}
\hline Variables & x Average & SD \\
\hline Emotional exhaustion (EE) & 22.90 & 11.68 \\
\hline Depersonalization (DEP) & 8.1 & 6.08 \\
\hline Personal accomplishment (PA) & 27.63 & 9.31 \\
\hline General MBI burnout rate & 45.6 & $(16.96)$ \\
\hline SD - standard deviation & &
\end{tabular}

Table 3. The values of descriptive statistics for the SWING questionnaire variables

\begin{tabular}{|c|c|c|c|c|c|}
\hline Variables & Average & SD & $\mathrm{Me}$ & Maximum value & Minimum value \\
\hline Negative home-work relation & & & 0.5 & 1.75 & 0 \\
\hline Positive work-home relation & 1.28 & 0.47 & & 2.6 & 0.2 \\
\hline Positive home-work relation & 1.3 & 0.52 & & 2.8 & 0 \\
\hline
\end{tabular}

SD-standard deviation, Me-median 
Table 4. Correlations between work-home interactions and emotional exhaustion, depersonalisation, and personal accomplishment

\begin{tabular}{lccc}
\hline Variables & Emotional exhaustion & Depersonalisation & Personal accomplishment \\
\hline Negative work-home relation $r$ & 0.51 & 0.32 & -0.13 \\
$p$ & $<0.01$ & 0.001 & 0.21 \\
\hline Negative home-work relation $r$ & 0.13 & 0.26 & -0.28 \\
$p$ & 0.19 & 0.01 & 0.01 \\
\hline Positive work-home relation $r$ & -0.45 & -0.21 & 0.25 \\
$p$ & $<0.001$ & 0.04 & 0.01 \\
\hline Positive home-work relation $r$ & -0.18 & -0.04 & 0.12 \\
$p$ & 0.07 & 0.69 & 0.25 \\
\hline
\end{tabular}

$p$-statistical significance coefficient, $r$ - Pearson's correlation

The lowest value was 0.2, whereas the highest value reached 2.6 (Table 3). The most frequent comments made by nurses implied that they were better at meeting deadlines at home because this was what their work required from them, that they were better at managing their private time also due to the way in which they worked, or that their relations with their partners (family or friends) were better thanks to the things that they learned at work.

The distribution of subscale values for positive home-work interaction did not deviate from normal distribution, with an average value of $1.3(\mathrm{SD}=0.52$ ). The minimum value was 0 , whereas the maximum value reached 2.8 (Table 3). The most frequent comments made by nurses implied that they got more satisfaction from work after an enjoyable weekend spent with their partners (family or friends), that they were better at managing their time at work because they had to do it at home as well, or that their attitude to their work duties was more serious because the same was required from them at home.

\section{Work-home, home-work correlations and occupational burnout}

Table 4 presents the findings of the study, which describe the correlations between SWING questionnaire variables and a high level of emotional exhaustion, high level of depersonalisation, and a low sense of personal accomplishment.

Emotional exhaustion and depersonalisation were positively correlated with a negative work- home relation. A higher value of emotional exhaustion was frequently correlated with a negative work-home relation. Similarly, higher values of depersonalisation were often accompanied by a more frequent incidence of negative work-home relations.

Depersonalisation and work satisfaction were connected with a negative home-work relation. A positive correlation was observed between depersonalisation and a negative home-work relation. A negative homework relation was more common in the respondents with a higher level of depersonalisation. Personal accomplishment was negatively correlated with a nega- tive home-work relation. Along with an increase in the sense of personal accomplishment, a decrease in negative home-work relation was observed. However, no significant correlation was observed between emotional exhaustion and a negative home-work relation.

All the subscales of occupational burnout were connected with a positive work-home relation. A negative correlation was observed between emotional exhaustion and depersonalisation and a positive work-home relation. A higher value of the subscale describing positive work-home relation was correlated with a lower value of emotional exhaustion and lower value of depersonalisation. Job satisfaction was positively correlated with a positive work-home relation (the higher the sense of personal accomplishment, the higher the values of the positive work-home relation). No significant correlations were observed between positive home-work relation and the analysed dimensions of occupational burnout. Depersonalisation and a lowered sense of personal accomplishment were not significantly correlated with a positive home-work relation. A negative correlation was observed between emotional exhaustion and a positive home-work relation, but the difference was not statistically significant $(r=-0.18$, $p=0.07)$

\section{DISCUSSION}

The objective of the study was to present the correlations between occupational burnout and workhome interactions in hospital-employed nurses. Another important aspect was the impact of positive and negative work-home and home-work relations on occupational burnout.

Nurses are more likely to experience negative work-home relations than negative home-work relations. Problems at work result in dissatisfaction from work, work-related stress, and problems with organisational involvement. They have an influence on family life as well [17]. Nurses' problems at work are often reflected in their family life, leading to more conflicts at home, which are caused by work requirements $[16,18,19]$. The group examined in the study 
comprised over $98 \%$ women. Numerous studies have proven that women are more likely than men to experience conflicts in the sphere of work-home, homework relations [20-23]. The study by Lo et al. [24] also showed that women without their husband's or partner's support are more likely to experience work or family conflicts.

Although nowadays women participate in professional life much more frequently than they used to, the gender roles have not changed much. Going to work and earning money is still the main role of men, whereas women are expected to do housework and look after children [25]. As a result, women are often poised between household duties and the requirements of professional work. Men, in turn, following traditional gender roles, have priority as far as work and earning money are concerned. From a traditional point of view, employment and pursuing professional career should be of secondary importance for women. The most important aspects seem to be getting married, looking after children, and keeping their husbands happy. Even if a woman has a job and pursues her career, she spends much more time doing housework than her husband or partner.

The authors' own study additionally showed a positive correlation of a negative work-home relation and emotional exhaustion and depersonalisation. The findings are congruent with the results of the study conducted by Iskra-Golec et al. and a few metaanalyses of the study results [7, 17, 26, 27]. An analysis conducted by Debris and Baka shows that social support decreases the negative impact of work-home relations on respondents' psychological health [28].

No significant correlation was observed in this study between emotional exhaustion and a negative work-home relation, which was observed by other authors [7, 29, 30]. However, there were significant correlations as far as depersonalisation and job satisfaction are concerned. A positive correlation was also found between depersonalisation and a negative home-work relation and a negative correlation between a lowered sense of personal accomplishment and a negative home-work relation.

The study showed that all the subscales of occupational burnout were correlated with a positive work-home relation. It was observed, just like in the study conducted by Iskra-Golec, that a positive work-home relation reduces emotional exhaustion, decreases the intensity of depersonalisation, and increases the sense of personal accomplishment. No significant correlations were observed between a positive home-work relation and the analysed dimensions of occupational burnout; however, a negative correlation was detected between emotional exhaustion and a positive home-work relation. Positive work-home and home-work relations are connected with facilitation and enrichment. Facilitation means the extent to which one's involvement in family life or work contributes to their functioning in the other sphere [31]. In turn, enrichment means the degree to which the experience gained from one role improves one's functioning in the other role by a two-way flow of resources [32].

Limitations of this study include the homogeneity of the group as far as the nurses' gender is concerned and a small number of respondents, which limits the generalisation of the findings. The findings of the study emphasise the importance of introducing profamily policies in the nursing environment (especially in hospitals), with the aim of limiting negative correlation between work and family life. It should be a priority in occupational burnout prevention and, consequently, in stopping nurses from quitting their jobs.

\section{Disclosure}

The authors declare no conflict of interest.

\section{References}

1. Freudenberger HJ. Staff burn-out. J Soc Issues 1974; 30: 159-165.

2. Maslach C. Burnout: the cost of caring. Englewood's Cliffs NJ, Prentice-Hall 1982.

3. Maslach C, Leiter MP. The truth about burnout: how organizations cause personal stress and what to do about it. Jossey-Bass, San Francisco CA 1997.

4. Aiken LH, Clarke SP, Sloane DM, et al. Hospital nurse staffing and patient mortality. nurse burnout. and job dissatisfaction. JAMA 2002; 288: 1987-1993.

5. Radkiewicz P, Widerszal-Bazyl MŁ, Pokorski J, et al. Dlaczego pielęgniarki tak wcześnie odchodzą z zawodu? Bezpieczeństwo Pracy 2004; 7-8: 31-34.

6. Wilczek-Rużyczka E. Wypalenie zawodowe pracowników medycznych. ABC Wolters Kluwer Business, Warszawa 2014.

7. Iskra-Golec I, Osikowska W, Siemiginowska P, et al. Relacja praca-rodzina, wypalenie zawodowe i zdrowie u pracujących na zmiany strażników miejskich. Czasopismo Psychologiczne 2014; 20: 281-293.

8. Maxwell AG, McDougall M. Work-life balance: exploring the connections between levels of influence in the UK public sector. Publ Manag Rev 2004; 6: 377-393.

9. Greenhaus HJ, Collins MK, Shaw DJ. The relation between work-family balance and quality of life. J Vocat Behav 2003; 63: 510-531.

10. Peeters MCW, Montgomery AJ, Bakker AB, et al. Balancing work and home: how job and home demands are related to burnout. Int J Stress Manag 2005; 12: 43-61.

11. McNall LA, Nicklin JM, Masuda AD. A metaanalytic review of the consequences associated with work-family enrichment. J Business Psychol 2010; 25: 381-396.

12. Masuda A, McNall L, Allen T, Nicklin J. Examining the constructs of work-to-family enrichment and positive spillover. J Vocat Behav 2012; 80: 197-210.

13. Maslach C, Jackson S, Leiter M. Maslach Burnout Inventory Manual. 3rd ed. Consulting Psychologists Press, Mountain View CA 1996.

14. Pasikowski T. Polska adaptacja Maslach Bernout Inventory. In: Sęk H (ed.). Wypalenie zawodowe. Przyczyny. Mechanizmy. Zapobieganie. PWN, Warszawa 2002; 135-148. 
15. Mościcka-Teske A, Merecz D. Polska adaptacja kwestionariusza SWING do diagnozy interakcji praca-dom i dom-praca. Medycyna Pracy 2012; 63: 355-369.

16. Geurts S, Taris T, Kompier M, et al. Work-home interaction from a phychological perspective: Development and validation of a new questionnaire: the SWING. Work and Stress 2005; 19: 319-339.

17. Allen TD, Herst DE, Brück CS, Sutton M. Consequences associated with work-to-family conflict: a review and agenda for future research. J Occup Health Psychol 2000; 2: 278-308.

18. Anafarta N. The relationship between work-family conflict and job satisfaction: A structural equation modeling (SEM) approach. Int J Business Manag 2011; 4: 168-177.

19. Kinnunen U, Geurts S, Mauno S. Work-to-family conflict and its relationship with satisfaction and well-being: A one-year longitudinal study on gender difference. Work and Stress 2004; 1: 4919-4924.

20. Duxburry L, Higgins C. Employed mothers: Balancing work and family life. Canadian Centre for Management Development, Ottawa 1994.

21. Tremblay DG. Work-Family Balance: What are the sources of difficulties and what could be done? Canada Research chair on the socio-organizational challenges of the knowledge economy. Tele-Universite, Universite de Quebec, 2004.

22. Byron K. A meta-analytic review of work-family conflict and its antecedents. J Vocat Behav 2005; 67: 169-198.

23. Carlson DS, Perrewe PL. The role of social support in the stressor-strain relationship: an examination of work-family conflict. J Manag 1999; 25: 513-540.

24. Lo S, Stone R, Catherine W. Work-family conflict and coping strategies adopted by female married professionals in Hong Kong. Women Manag Rev 2003; 4: 182-190.

25. Windebank J. Dual-earner couples in Britain and France: Gender divisions of domestic labour and parenting work in different welfare states. Work Employment and Society 2001; 2: 269-290.

26. Gürcü E, Hüsne D. Investigation of work-family. family-work conflict of the teachers. Procedia - Soc Behav Sci 2014; 116: 4919-4924.

27. Allen T. The work-family role interface: A synthesis of the research form industrial and organizational psychology. In: Weiner IB (ed.). Handbook of psychology Hoboken. John Wiley and Sons Inc., New Jersey 2013; 698-718.

28. Baka Ł. Zależność między konfliktami praca-rodzina i rodzinapraca a zdrowiem pielęgniarek - buforujący efekt wsparcia społecznego. Medycyna Pracy 2013; 64: 775-784.

29. Brauchli R, Bauer GF, Hämmig O. A cross-sectional study among employees in four large Swiss enterprises. Swiss J Psychol 2011; 3: 165-174.

30. Wang Y, Chang Y, Fu J, Wang L. Work-family conflict and burnout among Chinese female nurses: the mediating effect of psychological capital. BMC Public Health 2012; 12: 915.

31. Carlson DS, Kacmar MK, Williams LJ. Construction and validation of a multidimensional measure of work-family conflict. J Vocat Behav 2000; 56: 249-276.

32. Greenhaus JH, Powell GN. When work and family collide: Deciding between competing role demands. Organisational Behaviour and the Human Decision Processes 2003; 2: 291-303. 